\title{
МЕТОДИКА КАРТОГРАФИЧЕСКИХ ИЗМЕРЕНИЙ ЭЛЕМЕНТОВ РАСТИТЕЛЬНОГО ПОКРОВА ГОРОДСКОЙ ЗОНЫ ЗАСТРОЙКИ МНОГОЭТАЖНЫМИ ЖИЛЫМИ ДОМАМИ
}

\author{
${ }^{1}$ Кудряшова А.И. \\ ${ }^{1}$ ФГБОУ ВПО «Поволжский государственный технологический университет». Россия, Рес- \\ публика Марий Эл, 424000, г. Йошкар-Ола, пл. Ленина, д. 3. e-mail: Little-one7@yandex.ru
}

\begin{abstract}
Рассмотрены элементы растительного покрова в ГИС «Карта 2011» у 61 кадастрового квартала «Зоны застройки многоэтажными жилыми домами» г. Йошкар-Ола с 6141 земельными участками под древостоями и кустарниками. Суммированием определялась общая площадь элементов растительного покрова для каждого кадастрового квартала. Методика картографических измерений реализуется на существущих методах с использованием ГИС «Карта 2011» и в основном ориентирована на измерения периметра и площади земельных участков различных элементов растительного покрова (газоны, кустарники и древесные насаждения). При этом обвод контуров этих элементов выполняется вручную, поэтому предлагаемая методика пока является весьма трудоемким процессом. Разработана блок-схема процедур методики картографических измерений, содержащая шесть основных процедур, каждая из которых содержит 4-7 действий с объектом в виде элемента растительного покрова. Эти Элементы вполне можно принять за объекты кадастрового учета, однако в дальнейшем требуются более точные измерения геодезическими приборами периметра и площади земельных участков газонов, кустарников, древесных насаждений. В будущем необходиы геодезические съемки, например, лучшего кадастрового квартала для определения погрешности картографических измерений.

Ключевые слова: городские квартала, жилая зона, элементы, растительный покров, древостои и кустарники, кадастровый учет, закономерности.
\end{abstract}

\section{CARTOGRAPHIC METHODS OF MEASUREMENTS OF ELEMENTS OF THE VEGETATION COVER OF URBAN BUILT-UP AREA MULTI-STOREY RESIDENTIAL BUILDINGS}

\author{
${ }^{1}$ Kudryashova A. I. \\ ${ }^{1}$ Volga state technological University. 3, Lenin sq. Republic of Mari El, Yoshkar-Ola, 424000, \\ Russia.e-mail: Little-one7@yandex.ru
}

The elements of vegetation cover in GIS "Map 2011" 61 cadastral quarter "of the built-up Area multistory residential buildings," Yoshkar-Ola with 6141 land under stands of trees and shrubs. Was determined by summing the total area of the elements of vegetation cover for each cadastral district. The method of mapping measurement is implemented on existing practices using GIS "Map 2011" and focus on measuring the perimeter and area of different land elements of vegetation (lawns, shrubs and tree plantings). The bypass circuits of these elements is done manually, so the proposed method is still time consuming. Developed flowchart and procedures, cartographic measurements, containing six main procedures, each of which contains 4 to 7 actions with an object as an item of vegetation. These elements may well be mistaken for the objects of the cadastral account, however further requires more precise geodetic measurement instruments perimeter and area of the land plots of lawns, shrubs, trees. In the future the necessary survey, for example, the best of cadastral quarter to determine the error map measurements.

Key words: urban block, housing area, the elements, vegetation, trees and shrubs, cadastre, laws.

Устойчивое развитие городов для создания комфортной среды обитания является главной тенденцией XXI века. В архитектурном проектировании зеленые насаждения становятся важными элементами городской среды. Под устойчивым развитием понимается такая модель развития общества, в которой удовлетворение потребностей настоящего поколения не ставит под угрозу возможность для будущих поколений удовлетворять в полной мере потребности. 
Концепция устойчивого развития формировалась в ходе постепенного осознания обществом природоохранных, экономических и социальных проблем, оказывающих влияние на состояние природной среды. Это - конструктивная реакция общества на наблюдаемые и активно освещаемые в научных публикациях и средствах массовой информации процессы деградации природы под усиленным антропогенным давлением [8].

Финляндия отличается невероятным прогрессом в создании комфортной городской среды. В основе лежит эффективное сотрудничество архитекторов, строителей, органов власти и местных сообществ. В 2012 г. Международный совет по промышленному дизайну назвал Хельсинки «Столицей мирового дизайна». На форуме 23-28 апреля 2015 г. в Хельсинки были рассмотрены меры, как сделать городскую среду устойчивой и привлекательной [9].

Для нашей статьи применим девиз «Умный - значит зелёный». Однако на элементы растительного покрова не обращается достаточного картографического внимания.

Цель статьи - показать на примере города Йошкар-Ола, одного из экологических центров Приволжского федерального округа, методику картографических измерений элементов растительного покрова в городской зоне застройки многоэтажными жилыми домами

В работе использовались картографические данные из www.gisinfo.ru, материалы собственных полевых измерений, факторного анализа статистических данных. В процессе решения теоретических и практических задач применялись методы математического моделирования, статистики, а также программы Table Curve 3D, Curve expert-1.38, Microsoft Excel.

Генеральный план (рис. 1) городского округа "Город Йошкар-Ола" [1] - столицы субъекта Российской Федерации Республики Марий Эл - разработан в 2004-2007 гг., научнопроектным институтом пространственного планирования "ЭНКО" (Санкт-Петербург).

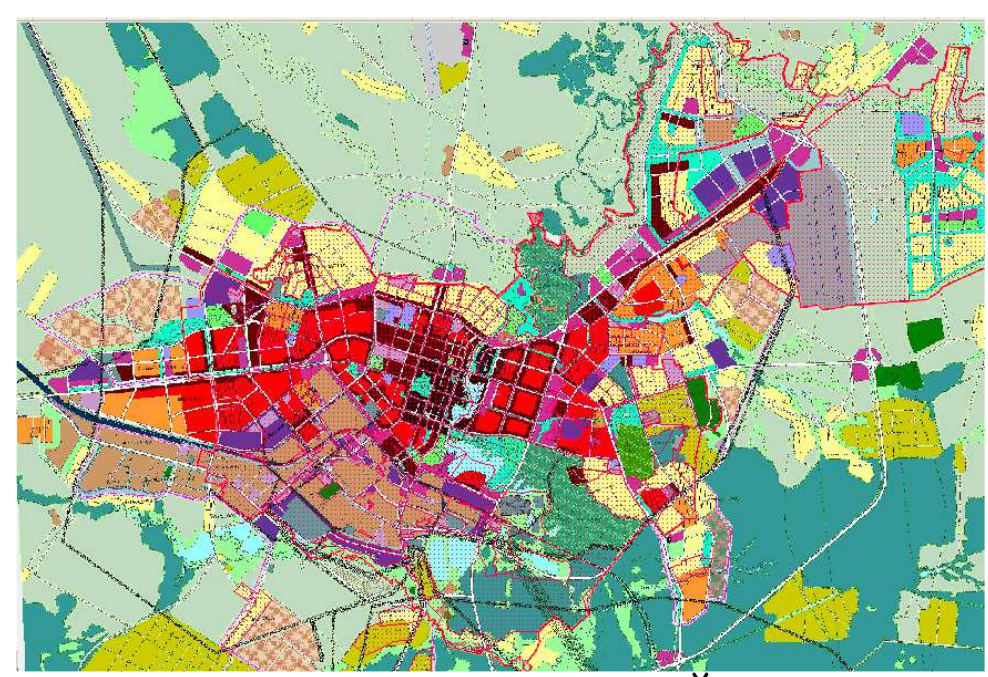

Рис. 1. Генеральный план города Йшкар-Ола

Он был выполнен с учетом Градостроительного кодекса РФ (2004 г.), Земельного кодекса РФ (2001 г.), Федерального закона от 6 октября 2003 г. № 131-Ф3 "Об общих принципах организации местного самоуправления в Российской Федерации", других законов и федеральных нормативных актов.

Из Генерального плана города нами был выделена основная часть в количестве 303 кадастровых кварталов (рис.2), по которым в ГИС «Карта-2011»[2] были выделены условные координаты, периметр и площадь квартала (табл. 1) в урезанной местной системе координат МСК-12. 


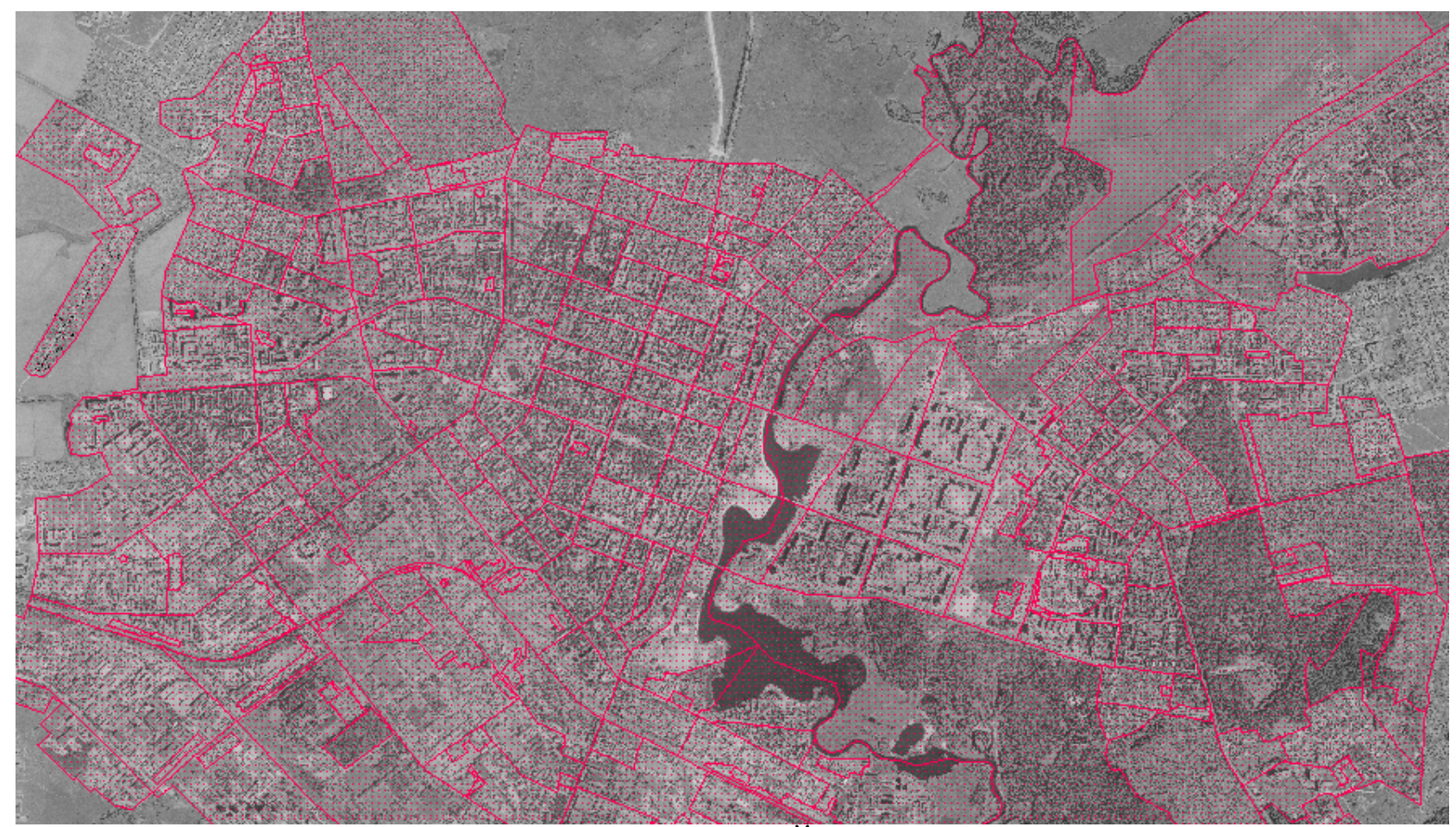

Рис. 2. Кадастровые городские кварталы Йошкар-Ола в ГИС «Карта-2011»

Таблица 1

Данные городских кварталов в зоне застройки многоэтажными жилыми домами

\begin{tabular}{|c|c|c|c|c|c|c|c|c|}
\hline \multirow{2}{*}{$\begin{array}{l}\text { № } \\
\Pi / \Pi\end{array}$} & \multirow{2}{*}{$\begin{array}{c}\text { № } \\
\text { по } \\
\text { городу }\end{array}$} & \multirow[t]{2}{*}{ Код } & \multicolumn{2}{|c|}{$\begin{array}{c}\text { Координаты } \\
\text { центра квартала }\end{array}$} & \multicolumn{2}{|c|}{$\begin{array}{c}\text { Параметры } \\
\text { квартала }\end{array}$} & \multicolumn{2}{|c|}{$\begin{array}{c}\text { Параметр } \\
\text { формы квартала } \\
\end{array}$} \\
\hline & & & $x, \mathrm{M}$ & $y, \mathrm{M}$ & $P, \mathrm{M}$ & $S, \mathrm{M}^{2}$ & $S / P, \mathrm{M}$ & $100 S / P^{2}, \%$ \\
\hline 1 & 2 & 11 & 4087 & 10090 & 1440 & 113639 & 78.94 & 5.48 \\
\hline 2 & 4 & 11 & 8578 & 10552 & 1184 & 80294 & 67.81 & 5.73 \\
\hline 3 & 5 & 11 & 9335 & 11373 & 1475 & 107570 & 72.95 & 4.95 \\
\hline 4 & 9 & 11 & 9042 & 10861 & 1631 & 157486 & 96.56 & 5.92 \\
\hline 5 & 10 & 11 & 4969 & 10083 & 2170 & 164374 & 75.74 & 3.49 \\
\hline$\ldots$ & $\cdots$ & $\ldots$ & $\ldots$ & $\ldots$ & & & & \\
\hline 57 & 290 & 11 & 8657 & 9728 & 2789 & 150242 & 53.88 & 1.93 \\
\hline 58 & 292 & 11 & 3474 & 11807 & 1696 & 175085 & 103.23 & 6.09 \\
\hline 59 & 296 & 11 & 4658 & 10179 & 1849 & 186932 & 101.12 & 5.47 \\
\hline 60 & 300 & 11 & 2311 & 10773 & 2944 & 303212 & 102.99 & 3.50 \\
\hline 61 & 302 & 11 & 4047 & 11932 & 2355 & 238139 & 101.11 & 4.29 \\
\hline
\end{tabular}

Примечание: из 61 кадастровых квартала затем три были исключены.

В таблице 1 даны следующие условные обозначения:

$x$ - условная абсцисса центра кадастрового квартала по широте Y, м;

$y$ - условная ордината центра кадастрового квартала по долготе X, м;

$P$ - периметр кадастрового квартала, м;

$S$ - площадь кадастрового квартала, м $^{2}$

$s$ - коэффициент абсолютной формы $s=S / P$;

$\gamma$ - коэффициент относительной формы объекта $\gamma=100 S / P^{2}$. 
Дополнительно были рассчитаны предлагаемые параметры формы кадастрового квартала $[3,6]$. Для оценки возможности статистического моделирования вначале была рассмотрена совокупность из всех 303 кадастровых квартала, затем массив исходных данных из 204 кадастровых квартала, включающая по данным таблицы 1 три городские зоны и 10 подзон.

Процедуры картографических измерений приведены на рисунке 3.

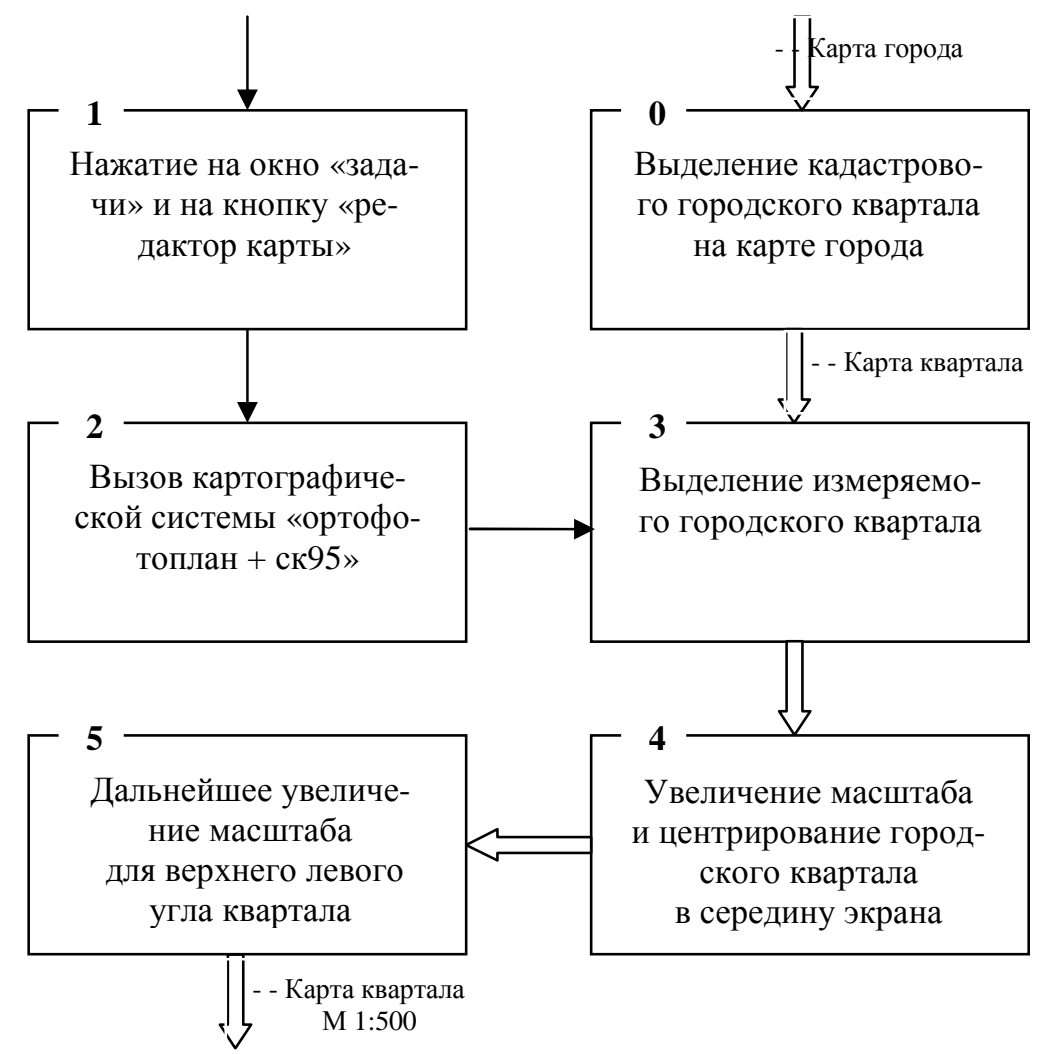

Рис. 3. Блок-схема процедур методики картографических измерений

Инструменты «Панорама» используются для улучшения рабочих процессов организации на базе географического подхода (рис. 4).

Для визуализации пространственной информации используются цифровые классификаторы для карт различной тематики. Классификаторы содержат информацию об объектах местности, их атрибутах, порядке группировки объектов в слои и условные знаки для отображения. Траектория движения взгляда оператора при выделении трех видов объекта:

1) газон;

2) кустарник обычный;

3) древесные насаждения;

Вначале в левом верхнем углу выделенного городского квартала располагаются деревья. За первый объект принимается древесное насаждение. Эта траектория принимается по принципу движения стрелок часов слева направо или по часовой стрелке.

При этом образуется ломанная линия с вертикальными движениями на размер максимального элемента растительного покрова. 


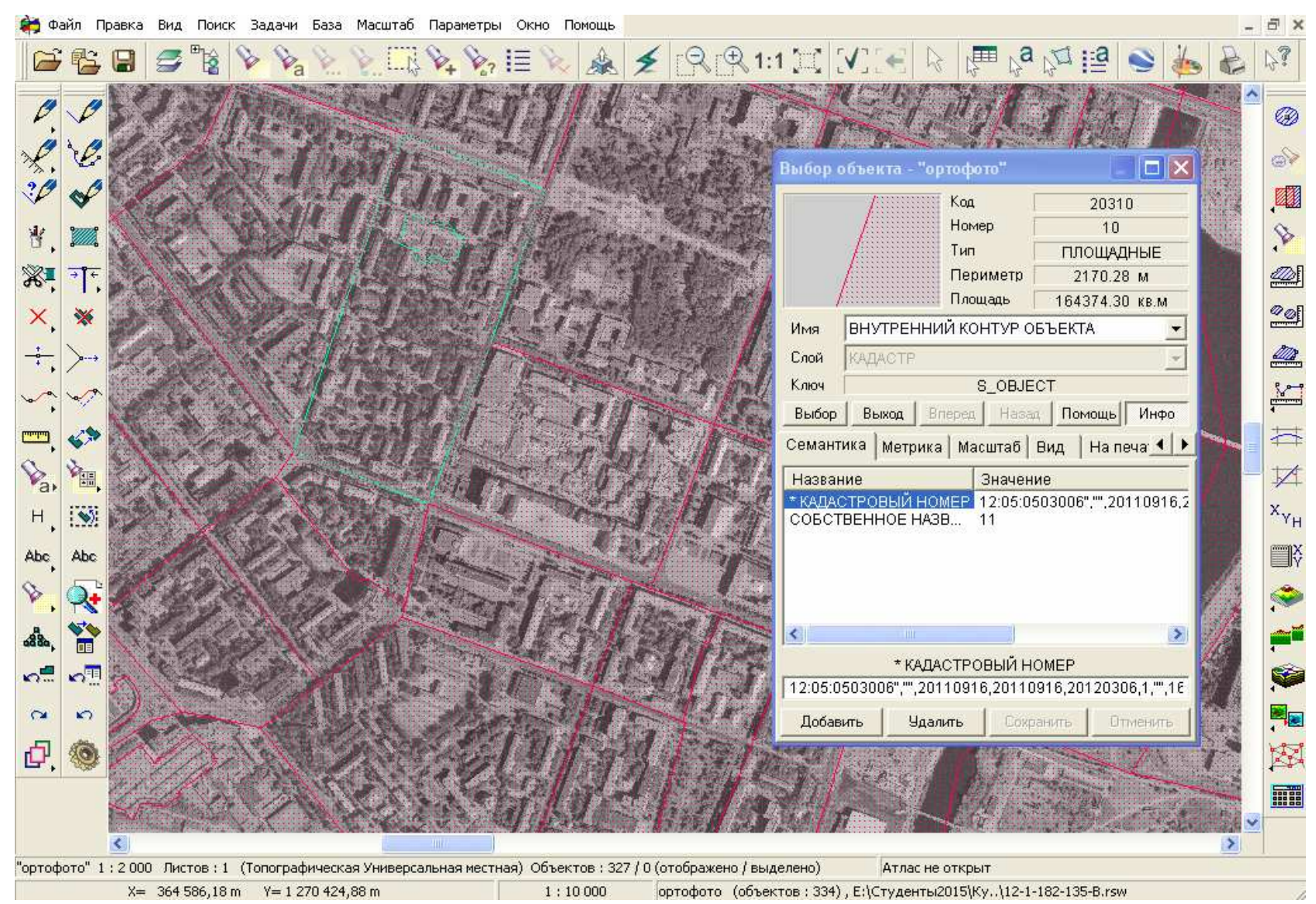

Рис. 4. Выделение измеряемого городского квартала

Для начала работы с векторными объектами активизируем панель Редактор карты в меню Задачи. Выберем операцию Создание объекта. Окно Создание объекта состоит из разделов: - окно выбора действующей карты; - раздел Изображение; - раздел Слои с перечнем слоёв карты; - раздел Список объектов с перечнем объектов, принадлежащих каждому слою (верху предоставлены кнопки с возможностью выбора отображения списка); - раздел Способ нанесения объекта; - раздел Поиск, который предоставляет возможность поиска объектов по названию, коду и ключу.

Процесс создания объекта начинается с выбора типа создаваемого объекта. В окне Создание объекта установлена карта, на которую будет наноситься объект. Установлен характер локализации создаваемого объекта. Для данного примера это Площуадной объект. Выбран слой отображения, к которому принадлежит создаваемый объект - Растительность. Выбрав сам объект из списка названий объектов - Древесное насаждение (парк). Образец отображения на карте выбранного объекта отображается во вспомогательном окне.

Площадной объект, также как и линейный, может быть создан несколькими разными способами. На примере создания Древесное насаждение (парк) нанесем объекты наиболее удобным способом: режим Описывающий сплайн доступен для создания линейных, площадных объектов. При создании объекта точки указываются на экране курсором, автоматически выстраиваемая плавная кривая пройдет точно через указанные точки, сглаживая их углы. 
После выбора нужного объекта нажатием кнопки Выбор, рисуем объект на карте. По завершению операции создания объекта появляется диалог со списком всех семантических характеристик, которые могут быть назначены данному объекту карты.

При необходимости пользователи могут заполнить нужные семантики. Элементы растительного покрова (газон, кустарник, древостой) выделяются, как списки объектов, на каждом кадастровом квартале.

При создании объекта точки указываются на экране курсором, автоматически выстраиваемая плавная кривая пройдет точно через указанные точки, сглаживая их углы. С помощью команды «Выделить указанные» точечная лилия границы древостоя была превращена в сплошную линию.

На рисунке 5 приведен пример формирования списка элементов растительного покрова $[4,5,7]$ по верхней части кадастрового квартала. Общий список объектов на одном кадастровом квартале достигает до 240 штук и более (древостоев и кустарников).

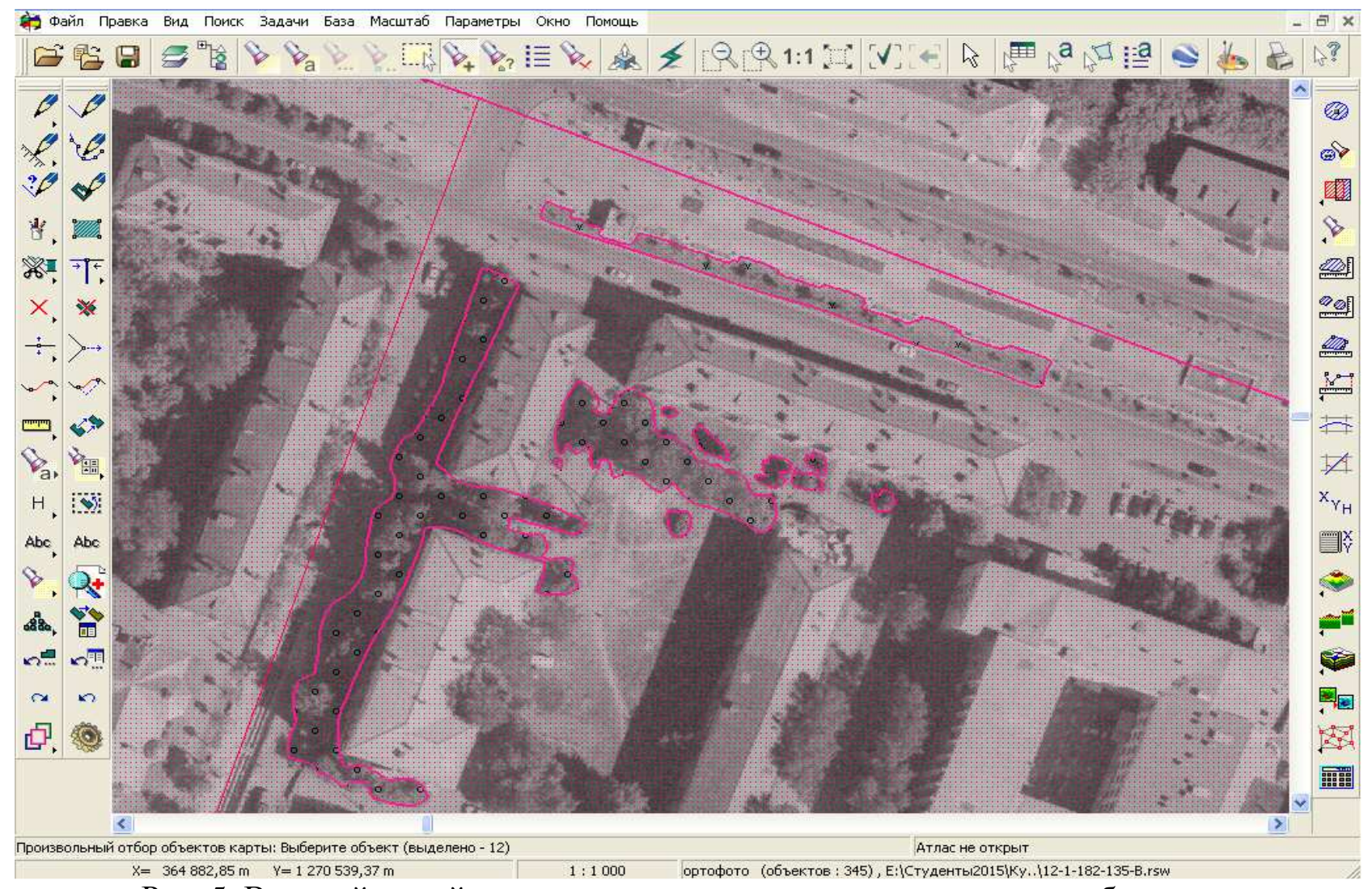

Рис. 5. Верхний левый угол городского квартала с выделенными объектами (два древесных насаждения, один газон и несколько кустарников)

Постепенно формируется список объектов на каждом кадастровом квартале. Дополнительно к основным параметрам (периметр и площадь) рассчитываются другие показатели.

Методика картографических измерений реализуется на существующих методах ГИС «Карта 2011» и в основном ориентирована на измерения периметра и площади земельных участков различных элементов растительного покрова (газоны, кустарники и древесные на- 
саждения). При этом обвод контуров этих элементов выполняется вручную, поэтому предлагаемая методика пока является весьма трудоемким процессом.

На основе накопленного нашего опыта измерений были сформулированы следующие основные выводы:

1) в городе Йошкар-Ола газоны с клумбами представлены только на бульваре поперек реки, а в других местах они в основном заняты автомобильными парковками, которые располагаются среди кустарников и древесных насаждений, в будущем нужно разнообразить газоны, клумбы, цветники и на других улицах;

2) основной причиной отсутствия газонов является вытоптанные хаотично расположенные тропинки, поэтому фактически площадь под газонами велика, при регулировании их границ появятся и хорошие газоны, которые нужно огораживать бордюрами, бетонными оградками и пр.;

3) при обводе кустарника учитывался каждый куст в отдельности из-за того, что между кустами участок был вытоптан, поэтому в будущем участки кустарника необходимо огораживать для роста и развития травяного покрова, это приведет к симбиозу кустов и газона;

4) под множеством деревьев, как правило, присутствует травяной покров, поэтому обвод контура лесного насаждения не представляет затруднений: в итоге может образоваться комплексный элемент, включающий газон с кустами и деревьями;

5) разработана блок-схема процедур методики картографических измерений, содержащая шесть основных процедур, каждая из которых содержит 4-7 действий с объектом в виде элементов РП;

6) при обходе элемента РП по контуру траектория движения взгляда начинается с левого верхнего угла выделенного городского квартала, причем эта траектория принимается по часовой стрелке с образованием ломаной линии: при этом приходится изменять масштаб изображения и эта процедура становится сложной;

7) элементы растительного покрова вполне можно принять за объекты кадастрового учета, однако в дальнейшем требуются более точные измерения периметра и площади земельных участков растительности, кустарников, древесных насаждений; в будущем необходимы геодезические съемки, например, лучшего кадастрового квартала для определения погрешности картографических измерений.

Рекомендации производству. 1. В городе Йошкар-Ола газоны с клумбами представлены только на бульваре поперек реки, а в других местах они в основном заняты автомобильными парковками, которые располагаются среди кустарников и древесных насаждений, в будущем нужно разнообразить газоны, клумбы, цветники и на других улицах. Основной причиной отсутствия газонов является вытоптанные хаотично расположенные тропинки, по- 
этому фактически площадь под газонами велика, при регулировании их границ появятся и хорошие газоны, которые нужно огораживать бордюрами, бетонными оградками и пр.

2. В будущем необходимы геодезические съемки, лучшего кадастрового квартала среди растительности и древостоям №0303006, а среди кустарников 0703003. Эти съемки необходимы для определения погрешности картографических измерений.

3. Статистическое моделирование географического расположения центров городских кадастровых кварталов позволяет изучать архитектурные оси и направления застройки, в том числе и в динамике развития города. Наиболее устойчивой оказалась зона делового, общественного и коммерческого назначения. Доля участков, отнесенных к элементам природноэкологического каркаса, на урбанизированных территориях должна составлять $60 \%$.

4. Без моделирования можно определить рейтинг среди 58 кадастровых кварталов, входящих в подзону 11 «Знна застройки многоэтажными жилыми домами». Первое место получил кадастровый квартал №21, а последнее 58-е место - кадастровый квартал №17.

5. На лучшем квартале были рассмотрены элементы РП (древостои и кустарники вместе) с 222 элементами. С экологических позиций лучшим элементом РП стал участок №203, его необходимо тщательно обследовать геодезическими методами измерений.

\section{Список литературы}

1. Генеральный план городского округа «Город Йошкар-Ола». Решение Собрания депутатов городского округа "Город Йошкар-Ола" от 14.10.2011 № 323-V 2. - Йошкар-Ола, 2011. - 47 c.

2. Геоинформационная система «Карта 2011». Руководство пользователя. Версия 11. Ногинск: Панорама, 2011. - 141 c. www.gisinfo.ru

3. Мазуркин П. М. , Кудряшова А.И., Фадеев А.Н. Распределения кадастровых кварталов по подзонам жилой зоны города // Землеустройство, кадастр и мониторинг земель. 2015. - №8. - С. 61-70.

4. Мазуркин П. М., Кудряшова А.И. Закономерности онтогенеза листьев деревьев. Динамика роста листьев липы и березы в чистой и загрязненной автомобильными выхлопами городской среде / - Германия: LAB LAMBERT Academic Publishing, 2015. - 100 c. ISBN 9783-659-68893-2.

5. Мазуркин П. М., Кудряшова А.И. Динамика онтогенеза листьев дерева / - ЙошкарОла: ПГТУ, 2015. - 172 с.

6. Мазуркин П. М., Кудряшова А.И., Фадеев А.Н. Закономерности распределения кадастровых кварталов в общественно-деловой зоне города // Матер. междунар. научно-практ. конф. «Управление территорией: современные подходы и методы». - Пенза: ПГУАС, 2015. C. 58-62.

7. Мазуркин П. М., Кудряшова А.И., Фадеев А.Н. Закономерности распределения кадастровых участков города Йошкар-Ола // Труды Поволжского ГТУ. - Сер.: Технологическая. Вып. 3. - Йошкар-Ола: ПГТУ, 2015. - С.259-263.

8. Понятие устойчивого развития. URL: http://green-agency.ru/ponyatie-istoriya-i-sferyustojchivogo-razvitiya/ (Дата обращения 28.02.2015).

9. Создание комфортной городской среды XXI века. 23-28 апреля 2015, Финляндия. URL: http://green-agency.ru/best_urban/ (Дата обращения 18.02.2015). 


\section{Bibliography}

1. General plan of city district "City of Yoshkar-Ola." The decision of the Assembly of Deputies of the urban district "Yoshkar-Ola" from 14.10.2011 № 323-V 2. - Yoshkar-Ola, 2011. - 47 p.

2. Geographic Information System "Map 2011". User guide. Version 11 - Noginsk: Panorama, 2011. - 141 p. www.gisinfo.ru

3. Mazurkin P.M., Kudryashova A.I., Fadeev A.N. Distribution of cadastral quarters of subzones residential area of the city // Land management, a cadastre and monitoring of lands. - 2015. №8. - S. 61-70.

4. Mazurkin P.M., Kudryashova F.I. Laws of the ontogenesis of leaves of trees. The dynamics of growth leaf linden and birch trees in the clean and polluted urban environment, car exhaust / Germany: LAB LAMBERT Academic Publishing, 2015. - 100 p. ISBN 978-3-659-68893-2.

5. Mazurkin P.M., Kudryashova A.I. Dynamics ontogenesis tree leaves / - Yoshkar-Ola: Perm State Technical University, 2015. - 172 p.

6. Mazurkin P.M., Kudryashova A.I., Fadeev A.N. Laws of distribution of cadastral districts in social and business district of the city // Mater. Intern. Scient. Conf. "Management area: modern approaches and methods." - Penza: PGUAS, 2015. - P. 58-62.

7. Mazurkin P.M., Kudryashova A.I., Fadeev A.N. Laws of distribution of cadastral parcels Yoshkar-Ola Volga // Proceedings of the GTU. - Ser .: Technology. - Vol. 3. - Yoshkar-Ola: Perm State Technical University, 2015. - S.259-263.

8. The concept of sustainable development. URL: http://green-agency.ru/ponyatie-istoriya-isfery-ustojchivogo-razvitiya/ (Date Treatment 02/28/2015).

9. Creating a comfortable urban environment of the XXI century. April 23-28, 2015 in Finland. URL: http://green-agency.ru/best_urban/ (Date Treatment 02/18/2015).

Салихов Мухаммет Габдухаевич, д-р техн. наук, профессор, кафедра автомобильных дорог Поволжского ГТУ. Телефон (8362) 68-60-72.

Царев Евгений Михайлович, д-р техн. наук, профессор, кафедра технологии и оборудования лесопромышленных производств ПГТУ. Телефон (8362) 68-60-57. 